\title{
Theory of chromatography and its application to cation exchange in soils
}

\author{
P. Reiniger and G. H. Bolt
}

Biology Division of the European Communities, Joint Research Center, Ispra, Italy Department of Soils and Fertilizers, Agricultural University, Wageningen, the Netherlands

Received: 15 September 1972

\section{Summary}

The existing solutions of the differential equation describing the process of cation-exchange chromatography are compared and evaluated with respect to their applicability under conditions prevailing in soil. It is shown that in the case where divalent cations are replacing monovalent ions the exchange front assumes a stationary frofile at an early stage which then yields an analytical solution provided a rather simple exchange equation like the Gapon or the Vanselow equation applies. In the reverse situation (i.e. monovalent replacing divalent ions) a non-stationary front arises which is strongly dominated by the exchange equation and usually only weekly modified by diffusion and dispersion phenomena, allowing for a good approximation of the front by the analytical solution found in the absence of diffusion and dispersion. Knowledge of the total electrolyte in the soil column will often be the limiting factor for prediction of the location and shape of the exchange front.

\section{Introduction}

In soil science, theories of chromatography have been used to describe a number of processes, such as the movement of fertilizer bands (Levin, 1964), radioactive fallout (Frissel and Poelstra, 1967b), biocides (Lambert et al., 1965) and the redistribution of airborne salts in semi-arid soils (Yaalon, 1964). They have also been applied to problems of alkalinization and reclamation involving the movement and exchange of calcium, magnesium and sodium (Rible and Davis, 1955; van der Molen, 1957; Bower et al., 1957).

Recent literature reviews on chromatography were mainly written from the point of view of the industrial engineer or chemist (Glueckauf, 1955a; Vermeulen, 1958; Helferich, 1962a, b; 1965), aside from a review for application in geology (Ritchie, 1966) and in soil science (Frissel and Poelstra, 1967a). Two short and general introductions to the subject should also be mentioned (Martin, 1947; Giddings, 1967), as they reflect the development made in the span of twenty years.

There is certainly no lack of mathematical descriptions of chromatographic processes in the literature. On the contrary, it is rather the wealth of theoretical papers which may pose a problem to the soil scientist. Many of the existing treatises are written for specific industrial or analytical problems and for conditions which may be far from 
those applicable to soils. The main purpose of the present paper is to discuss the different types of solutions of the differential equation describing the process of cation exchange chromatography in view of their interrelations and their relevance to the soil system.

\section{Mathematical description of the chromatography process}

\section{2.l The conservation equation}

As all transport processes, exchange chromatography, following the movement of a salt solution through a porous exchanger, is subject to conservation equations for all ions involved, e.g. of the type:

$$
\frac{\partial\left(\mathrm{q}_{\mathrm{i}}+\varepsilon \mathrm{c}_{\mathrm{i}}\right)}{\partial \mathfrak{t}}=-\operatorname{div} \mathbf{J}_{\mathrm{i}}+\operatorname{prod}(\mathrm{i})
$$

in which $\mathrm{q}_{\mathrm{i}}$ is the amount adsorbed of ion $\mathrm{i}$, in meq per $\mathrm{cm}^{3}$ of the system; $\varepsilon \mathrm{c}_{\mathrm{i}}$ indicates the amount of the same ion present in the solution phase, with $\varepsilon$ solvent content in $\mathrm{cm}^{3}$ per $\mathrm{cm}^{3}$ of the system and $c_{i}=$ concentration; $J_{i}$ is the flux of the ion in meq $\mathrm{cm}^{-2} \mathrm{~s}^{-1}$ and prod(i) is a production term covering the appearence of the ion from e.g. dissolving salts.

The flux, $\mathbf{J}$, is for non-volatile components usually limited to the liquid phase and, therefore, consists of at least two terms, viz the convective flux, $(J)_{\text {con, }}$, and a diffusion flux, $(J)_{\text {diff }}$ (or dispersion flux, e.g. below), defined as:

$$
\begin{aligned}
& \left(\mathrm{J}_{\mathrm{i}}\right)_{\mathrm{con}}=\mathrm{vc}_{\mathrm{i}} \\
& \left(\mathrm{J}_{\mathrm{i}}\right)_{\text {diff }}=-\mathrm{D}_{\mathrm{i}} \operatorname{grad} \mathrm{c}_{\mathrm{i}}
\end{aligned}
$$

where $\mathrm{v}$ is the linear flow rate of the solution in $\mathrm{cm}^{3}$ per $\mathrm{cm}^{2}$ of the porous medium (including the solid phase exchanger) and $D_{i}$ is the effective diffusion coefficient of the ion in the system.

This effective diffusion coefficient may be estimated from the self-diffusion coefficients of all ions involved (as a weighted mean value) applying a correction for the liquid filled porosity and the tortuosity of the pores.

For a heterogeneous porous system (i.e. comprising a variety of sizes of interconnected pores) one has also to take into account the ion flux due to dispersion. For the present purpose (i.e. soil systems with comparatively low liquid velocities) the dispersion flux may be satisfactorily approximated by an expression like Eq. $2 b$ in which, in place of $\mathrm{D}$, a dispersion coefficient, $\mathrm{D}_{\text {disp }}$, is used, usually taken to be proportional to $\mathrm{v}$.

The production term is not easily expressed by a relationship of general validity. For dissolving (or precipitating) solid salts, it will be a rate function comprising both the locally existing concentration, $c_{i}$, and the concentration corresponding to equilibrium with the solid salt, $\mathrm{c}^{*}$ :

$$
\operatorname{prod}(\mathrm{i})=\mathbf{R}\left(\mathrm{c}_{\mathrm{i}}, \mathrm{c}_{\mathrm{i}}\right)
$$

For slowly dissolving salts, like gypsum, it should be satisfactory to take $\mathrm{R}$ proportional to the local concentration deficit $\left(\mathrm{c}^{*}{ }_{\mathrm{i}}-\mathrm{c}_{\mathrm{i}}\right)$.

Substituting Eq. 2 and 3 into Eq. 1, one finds for the case of particular interest, i.e. one dimensional flow with uniform macroscopic liquid velocity, the conservation equation for each ion to be: 


$$
\frac{\partial\left(q_{i}+\varepsilon c_{i}\right)}{\partial t}=-v \frac{\partial c_{i}}{\partial x}+D^{\prime} \frac{\partial^{2} c_{i}}{\partial x^{2}}+R\left(c^{*}{ }_{i}, c_{i}\right)
$$

where $\mathrm{D}^{\prime}$ covers both diffusion and dispersion phenomena.

\subsection{The adsorption equation}

Eq. 4 still contains two dependant variables, $q_{i}$ and $c_{i}$, which are related to each other by the adsorption equation. In its most general form such an equation may be written as:

$$
\mathrm{q}_{\mathrm{i} \mathrm{x}}^{\mathrm{t}}=\mathrm{q}\left(\mathrm{c}_{\mathrm{i}}, \mathrm{c}_{\mathrm{i}, \mathrm{k}} \ldots\right)_{\mathrm{x}+\Delta \mathrm{x}}^{\mathrm{t}-\Delta \mathrm{t}}
$$

This equation implies that the amount adsorbed of ion $i$ at time $t$ and position $x$ is in general a function of the concentration of $i$ and of all other (e.g. competing) ions in the solution at a time which may differ from $t$ and at a position in the column which may differ from $x$. The time lag, $\Delta \mathrm{t}$, arises when the rate of exchange is slow in comparison with the convection rate in the column. The distance lag, $\Delta x$, is the result of exchanger grains of finite size, the ionic composition of which is at best in equilibrium with the solution phase at the downstream end of the grain. In practice, the two phenomena are often interrelated as will be commented on in Section 3.

\subsection{The chromatography equation}

Eq. 4 and 5, written out for all ions except one (of which the solution concentration and amount adsorbed are determined by the condition of electroneutrality), may be combined to a set of (n-1) coupled differential equations containing ( $n-1)$ variables $c_{i}$. Provided suitable rate laws are available for dissolution and adsorption processes, such a set of equations may in principle be solved numerically with the help of a computer, although the computer time needed for such a solution may soon become prohibitive.

Fortunately many situations of primary interest in soil science are not nearly as complicated as suggested above. Thus, the alkalinization process following irrigation of soils with poor quality water and the reclamation process after leaching of the soil with e.g. gypsum-saturated water involves in principle only the exchange of $\mathrm{Ca}$ against $\mathrm{Na}$ plus, usually, a change in the anionic concentrations. As will be shown in Section 3, this change in anionic concentrations (for example, resulting from the introduction of highly saline water at the soil surface) is hardly of concern with respect to the prediction of the shape of the exchange 'front' in the soil. Thus, because of the absence of a sizable adsorption of anions like chloride, any change in the anionic concentration will be located far ahead of the exchange 'front' for the cations. Accordingly, the cation exchange chromatography may safely be regarded as taking place at a constant value of the anionic concentration equal to the concentration of the solution fed into the column. In turn, the concentration of $\mathrm{Ca}$ in and around the exchange front is then satisfactorily determined by the local concentration of $\mathrm{Na}$, and the amount of $\mathrm{Na}$ adsorbed then depends solely on the local concentration of this ion (aside from the lag factors mentioned above). In this case then, a single equation remains of the form:

$$
\left\{q^{\prime}(c)_{x+\Delta x}^{t-\Delta t}+\varepsilon\right\} \frac{\partial c}{\partial t}=-v \frac{\partial c}{\partial x}+D^{\prime} \frac{\partial^{2} c}{\partial x^{2}}+R\left(c^{*}, c\right)
$$

in which $\mathbf{q}^{\prime}$ stands for $\mathrm{dq} / \mathrm{dc}$, i.e. the differential capacity of the exchanger, in appropriate units. 
This equation should be regarded as the basic equation governing alkalinization and 'de-alkalinization' processes in soil. Provided suitable rate laws are available for the last term, a computer solution is now very well feasible. However, as these computer solutions have necessarily an incidental character, Section 3 presents a survey of the analytical solutions corresponding to certain simplified conditions. These solutions have the advantage that they may be applied straight away to many practical situations, provided the relevant simplifications are warranted.

\section{Analytical solutions of the chromatography equation}

As the presence of a production term usually necessitates the use of numerical solutions this term is left out of consideration. The large number of existing special solutions of Eq. 6 may then conveniently be classed according to the presence or absence of three simplifying characteristics of the system, viz:

1. the existence of instantaneous, local equilibrium between the adsorbed phase and the solution phase, i.e. $\Delta \mathrm{x}=\Delta \mathrm{t}=0$;

2. the validity of a linear adsorption (or exchange) isotherm, i.e. $q^{\prime}=\mathbf{k}=$ constant;

3. negligible effects of a diffusion term, i.e. $D^{\prime} / v \approx 0$.

These characteristics are listed in Table 1 from $A$ to $\mathrm{H}$ and, if applying, marked with a plus sign. Underneath, the relevant literature is mentioned.

The various existing analytical solutions for combinations A through $\mathbf{H}$ will now be treated individually in a short way. For a more extensive treatment the reader is referred to a review by Reiniger (1970) and the original literature.

\section{Case $A$}

This is the simplest case to be treated. It comprises the movement of an ion in a porous medium by convection only while being at constant equilibrium with the adsorbed phase and following a linear adsorption isotherm.

Consequently, Eq. 6 reduces to the simple form:

$$
\frac{\partial(\mathrm{kc}+\varepsilon \mathrm{c})}{\partial \mathrm{t}}=-\mathrm{v} \frac{\partial \mathrm{c}}{\partial \mathrm{x}}
$$

which gives after introduction of the total inflow volume, $\mathrm{V}(\mathrm{cm})$, the following solution for the position of the exchange front for the case of a block feed:

$$
\mathrm{x}_{\mathrm{p}}=\frac{\mathrm{V}}{\mathrm{k}+\varepsilon}
$$

Table 1. Schematic summary of existing specific solutions for the chromatography equation (Eq. 6).

\begin{tabular}{lcccccccc}
\hline Conditions & A & B & C & D & E & F & G & H \\
Equilibrium & + & + & + & + & - & - & - & - \\
Linear adsorption isotherm & + & - & + & - & + & + & - & - \\
Convection only & + & + & - & - & + & - & + & -
\end{tabular}

Solution worked out by De Vault (1943) and Walter (1945) in case B; Lapidus and Amundson (1952) in case C; Walter (1945) in case D; Wicke (1939), Glueckauf (1955) and Hougen and Marshall (1947) in case E; Lapidus and Amundson (1952) and Glueckauf et al. (1949) in case F; Thomas (1949) and Hiester and Vermeulen (1952) in case G. 
Thus the position of a 'block' exchange front, $x_{p}$ (to be termed 'equivalent depth of penetration' in the cases $B-H)$, is independent of the flow velocity. The factor $1 /(\mathrm{k}+\varepsilon)$, often expressed in terms of the distribution ratio, $\mathrm{r}_{\mathrm{D}} \equiv \mathrm{k} / \varepsilon$, signifies a 'shrinkage' factor, i.e. the factor by which the depth of infiltrating solution, $V$, is reduced for the ion under consideration during passage through the exchanger.

Solution 8 may be extended to a variable feed and initial column concentration and it is completely reversible.

\section{Case $B$}

Case $B$ differs from the previous basic case A only in the form of the exchange isotherm, which is now a continuous function of the concentration of the ion in solution. Therefore, for a block feed, the solution for Eq. 6 is comparable to Eq. 8 with $\mathrm{k}$ being replaced by $q^{\prime}(c)$ leading to:

$$
\mathrm{x}_{\mathrm{c}}=\frac{\mathrm{V}}{\mathrm{q}^{\prime}(\mathrm{c})+\varepsilon}
$$

Two types of isotherms often encountered in ion exchange are presented in Fig. 1, together with their first derivatives in respect to c. The convex or 'unfavourable' isotherm describes the exchange of a preferentially adsorbed cation like calcium by a cation having less affinity to the exchanger (i.e. sodium). The 'favourable' or concave isotherm describes the reverse exchange. As shown in Fig. 1 the slope, $q^{\prime}$, of an unfavourable isotherm is an increasing function of the concentration. Therefore, for a given depth of feed solution $\mathrm{V}$, according to Eq. 9 higher concentrations will penetrate to a
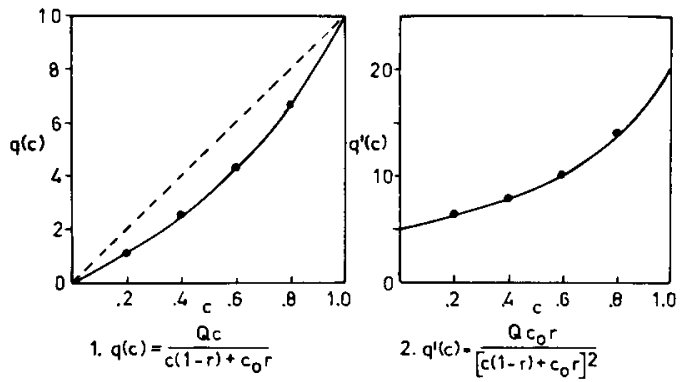

a. Unfavourable exchange isotherm: $r=\frac{1}{K}=2$
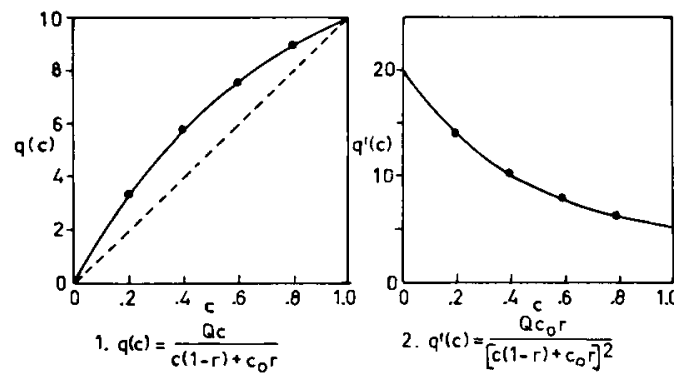

b. Favourable exchange isotherm: $r=\frac{1}{y}=1 / 2$
Fig. 1. Kerr exchange isotherm and differential capacity of the exchanger, $q^{\prime}(c)$. a. for unfavourable exchange b. for favourable exchange. 
shallower depth into the exchanger than lower ones thus flattening out the exchange front as it progresses in the column.

For the favourable isotherm, on the contrary, higher concentrations will advance faster than lower ones, thus steepening the concentration profile. As steepening of a block front is a physical impossibility, the depth of penetration of a preferentially absorbed cation will be given by the equivalent depth of penetration as defined by Eq. 8 with the distribution ratio expressed in terms of the slope of the chord of the exchange isotherm in the range under consideration, i.e. $\mathrm{r}_{\mathrm{D}}=\Delta \mathrm{q} / \varepsilon \Delta \mathrm{c}$.

Case $C$

While case $B$ formed a generalization of the ideal case $A$ regarding the form of the exchange isotherm, the present case $C$ represents a generalization of $A$ by retaining the diffusion term, i.e. a block feed entering the exchanger will only be modified by diffusion and dispersion phenomena. Accordingly, Eq. 6 takes the form of the FokkerPlanck equation describing random processes with a Gaussian distribution:

$$
\frac{\partial c}{\partial t}=D^{*} \frac{\partial^{2} c}{\partial x^{2}}-v^{*} \frac{\partial c}{\partial x}
$$

where $\mathrm{D}^{*}=\mathrm{D}^{\prime} /(\mathrm{k}+\varepsilon)=\left(\mathrm{D}+\mathrm{D}_{\text {disp }}\right) /\left(\mathrm{r}_{\mathrm{D}}+1\right) \varepsilon$

and $\mathrm{v}^{*}=\mathrm{v} /\left(\mathrm{r}_{\mathrm{D}}+1\right) \varepsilon$

$\mathrm{D}$ being the diffusion coefficient in the porous medium and $\mathrm{D}_{\mathrm{disp}}$ the hydrodynamic dispersion coefficient, presumably constant for a given exchanger and macroscopic flow velocity, v. For a block feed and a constant initial column concentration the solution of Eq. 10 is found as:

$$
c=c_{i}+1 / 2\left(c_{o}-c_{i}\right)\left[\operatorname{erfc} \frac{\left(x-v^{*} t\right)}{2 \sqrt{D^{*} t}}-e^{v^{*} x / D^{*}} \operatorname{erfc} \frac{\left(x+v^{*} t\right)}{2 \sqrt{D^{*} t}}\right]
$$

with $c_{i}$ being the initial concentration of the ion in the column and $c_{o}$ its concentration in the feed solution. Clearly, the second term within the brackets represents the reflection term caused by the entrance boundary, which term disappears rapidly with the advance of the exchange front.

Solutions for linear feed- and column concentration functions are given by Carslaw and Jaeger (1959) and they are valid for semi-infinite exchangers. The problem of finite exchange columns has been treated by Brenner (1962) and Bischoff and Levenspiel $(1962 a, b)$.

\section{Case D}

For this case, combining a non-linear exchange isotherm (B) and the diffusion-dispersion term (C), an analytical solution is possible for the specific system of a 'favourable' exchange isotherm such as governing the exchange of sodium by calcium. For an isotherm of this type, the flattening effect of the longitudinal diffusion and dispersion is balanced by the self-sharpening tendency of the exchange front and asymptotically this front attains a constant shape. For a block feed pattern this stationary profile is usually reached at a shallow depth in the exchange column (Lapidus and Rosen, 1954). The solution of Eq. 6 depends on the cation exchange isotherm employed. For complete mono-divalent exchange following a Gapon isotherm (Bolt, 1967) the solution is given by: 


$$
\mathrm{z}_{\mathrm{D}}=\frac{1}{1+\mathrm{r}} \ln \frac{(1+\sqrt{\mathrm{N}})}{(1-\mathrm{r} \sqrt{\bar{N}})}+\frac{1}{1-\mathrm{r}} \ln \frac{(1-\sqrt{\mathrm{N}})}{(1-\mathrm{r} \sqrt{\mathrm{N}})}+2 \ln (1-\mathrm{r} \sqrt{\mathbf{N}})+\text { const }
$$

where $z_{D}=\frac{\nabla}{D^{\prime}} \frac{Q}{Q+\varepsilon c_{o}}\left(x-x_{p}\right)$ is the reduced position parameter,

$\mathrm{N}=$ equivalent fraction of the divalent cation in solution

$\mathbf{r}=\mathrm{K}_{\mathrm{G}} \sqrt{2 \mathrm{c}_{\mathrm{o}}}$, with $\mathrm{K}_{\mathrm{G}}$ the Gapon exchange constant and

$\mathrm{Q}=$ exchange capacity, meq $\mathrm{cm}^{-3}$ of column.

The constant is best evaluated graphically from the equation:

$$
\text { constant }=-\int_{1}^{0} \mathrm{dN} \int^{\mathrm{N}} \frac{\mathrm{dN}^{\prime}}{\mathrm{n}-\mathrm{N}^{\prime}}-\frac{\mathrm{Q}}{\mathrm{Q}+\varepsilon \mathrm{c}_{\mathrm{o}}}
$$

in which $\mathrm{n}$ is the equivalent fraction on the adsorber in equilibrium with $\mathrm{N}^{\prime}$. A similar, though slightly more complicated equation may be derived for Gapon exchange over a limited range.

\section{Case E}

The introduction of non-equilibrium both in space and in time, combined with a linear adsorption isotherm in the absence of diffusion may lead to two types of solution for Eq. 6, an exact solution and an approximate one.

The approximate solution (Glueckauf, 1955) is valid for values of $v^{*} / \mathrm{R}$ (the ratio of the reduced velocity and a first-order rate coefficient $R$ of the exchange reaction) which are small in comparison to the 'width' of the exchange front. Then the solution given by Eq. 11 may be applied in which now $D^{*}$ is replaced by $D^{*}{ }_{R}$ according to:

$$
\mathrm{D}_{\mathrm{R}}^{*}=\frac{\left(\mathrm{v}^{*}\right)^{2}}{\mathrm{R}}\left(\frac{\mathrm{r}_{\mathrm{D}}}{\mathrm{r}_{\mathrm{D}}+1}\right)
$$

The distance lag arising from finite grain size as proposed by Glueckauf (1955a) may now of course be omitted as it arises because of assumed complete mixing within exchanger grains of finite size. On the other hand, it may be reasonable to assume that the rate coefficient, $R$, above is in effect the result of diffusion delay within exchanger particles. Then the particle size enters into $D_{R}^{*}$ in the form of $R=D_{p} / a^{2}$, with $D_{p}$ $=$ diffusion coefficient inside the particle, $\mathrm{d}=$ particle diameter and $\mathrm{a}=$ geometry factor. Thus $D^{*}{ }_{R}$ may be regarded as resulting from a time lag or caused by finite particle size.

The exact solution (Thomas, 1948; Mickley et al., 1957) is relevant for high flow velocities as encountered in chemical industry and is given by a $\mathrm{J}$-function available as graphs (Hiester and Vermeulen, 1952) or in tabulated form (Opler, 1953).

Case $F$

For values of $\mathrm{v}^{*} / \mathrm{R}$, small in comparison to the width of the exchange front, and a linear exchange isotherm the addition of longitudinal diffusion and dispersion to the previous case simply amounts to combining $D^{*}$ with $D^{*}$ into a total effective diffusion parameter, $D^{*}{ }_{T}$ (Klinkenberg and Sjenitzer, 1956; Houghton, 1963). The ratio $\mathrm{D}^{*} \mathrm{~T} / \mathrm{v}^{*}$ is commonly known as the 'height equivalence of a theoretical plate' or HETP (Glueck- 
auf, 1955b). The rather complex solutions for high $\mathrm{v}^{*} / \mathrm{R}$ ratios have been worked out by Wicke (1939) and Lapidus and Amundson (1952).

\section{Case $G$}

This combination of a non-linear exchange isotherm and non-equilibrium has found solutions for two particular cases.

The first solution is for a linear rate law and a 'favourable' exchange isotherm. The solution for this case, which implies the existence of a front of constant shape, is very similar, though not identical, to the one given in Eq. 12.

The second solution (Thomas, 1948; Hiester and Vermeulen, 1952) is for the special case of second order reversible kinetics. Though valid for both favourable and unfavourable exchange, this assumption is reasonable only for homovalent exchange and implies the validity of a Kerr type exchange equation. The solution is again in the form of $\mathbf{J}$ functions as mentioned under $\mathrm{E}$.

Case $H$

This most involved case has found no general analytical solution. An approximate solution has been worked out by Acrivos (1960) for the special combination of a first-order rate law, diffusion and a 'favourable' exchange isotherm, leading to a stationary front. This approximate solution is based on a weighted combination of concentration profiles resulting from diffusion (case $D$ ) and first-order rate effects (case $G$ ).

\section{Critical evaluation}

In this section it will be attempted to evaluate the solutions of the chromatography equation in view of conditions prevailing in a soil system. In essence, such evaluation implies assessing the acceptability of the simplifying assumptions used.

In doing so it is of prime importance to distinguish the leading effect in chromatography, i.e. redistribution of the inflowing ions over solid phase and solution in accordance with an integral conservation law, from all other effects which are modulating the actual front. This leading effect was treated in case A where, by neglecting all other effects, it was shown that a given feed pattern, i.e. a block feed, is found back in the column at an equivalent depth of penetration, $x_{p}$, depending solely on the distribution ratio of the ions between solid phase and solution. All other effects, treated separately and partly combined in the cases B-H now cause a modulation of the front in the column around this equivalent depth of penetration.

As follows from the above, any attempt to predict the distribution of ions fed into a soil column depends critically on the knowledge of the overall distribution ratio of the system. This ratio equals $\triangle q / \varepsilon \triangle \mathrm{c}$ as was discussed in case $\mathrm{B}$ above. It may be found from equilibrium experiments or may be estimated with the aid of an exchange equation. In the latter case the total electrolyte concentration in the soil solution is of prime concern, as in cation exchange (in contrast to simple adsorption) it is always the ratio of the concentration of the ion fed into the column to its competitors which determines its amount adsorbed.

After this leading factor has been evaluated, the action of the front-modulating effects should be considered. These effects, as treated in the previous sections, are:

a. The effect of the exchange isotherm (case $\mathrm{B}$ )

$b$. Diffusion and dispersion effects (case C)

c. Rate effects (delayed equilibrium due to finite rate of exchange, case $E$ ). 
The effects $b$ and $c$ act always in the direction of fattening the front but are limited in magnitude by the values of the effective diffusion, dispersion and rate coefficients relative to the convection velocity. The ranges of these coefficients and of the convection velocity are fortunately not too wide for most soils under conditions of practical concern. In contrast, $a$, the effect of the exchange isotherm, may be either in the direction of a flattening-out of the front (unfavourable isotherm) or in the opposite direction (favourable isotherm), or also 'neutral' (i.e. maintaining the front, for the case of the linear isotherm). At the same time the magnitude of this effect is highly variable and may be quite large, as the selectivity coefficient for different ion pairs in soils varies over a wide range.

In order to evaluate the relative significance of all these front modulating effects when present simultaneously it is necessary to distinguish the three possibilities with regard to effect $a$ as:

a 1. Favourable isotherm

a 2. Linear isotherm

a 3. Unfavourable isotherm

\section{a 1. The modulation of the front for the favourable isotherm}

In this case the exchange front has the tendency to steepen upon passage, because the distribution ratio at low saturation of the exchanger with a given ion exceeds that at high saturation. This tendency counteracts the flattening due to $b$ and $c$, and thus a stationary front pattern arises, in which the width of the front is determined by the relative magnitude of the effects $a$ versus $b$ plus $c$.

This situation deserves some special attention as it occurs commonly in reclamation procedures of soils where $\mathrm{Ca}$ ions are fed into a soil containing a high percentage of exchangeable $\mathrm{Na}$ ions. Here the rather convenient conclusion seems warranted that a rough guess at the magnitude of the effective diffusion coefficient including, if necessary, a contribution of $D_{R}$ allows one to indicate the approximate width of the stationary exchange front if the (static) exchange isotherm is known. As the mean (equivalent) depth is determined by the overall distribution ratio, it thus appears not so difficult to delineate the distribution of $\mathrm{Ca}$ ions following a reclamation procedure with an accuracy sufficient for practical purposes.

As follows from the calculations for case $\mathrm{D}$ the width of the stationary band following a Gapon exchange equation may be found by applying Eq. 12 twice with values of $\mathrm{N}$ corresponding to, for instance, 60 and $95 \%$ of exchange, respectively. Doing so, while using $\mathrm{K}_{\mathrm{G}}=1 / 2\left(\mathrm{~mol} / \mathrm{l}^{-1 / 2}, \mathrm{c}_{\mathrm{o}}=0.02 \mathrm{eq} / 1\right.$ and $\mathrm{D}^{*} / \mathrm{v}^{*}=0.1 \mathrm{~cm}$, one finds for the width of the stationary front about $0.1 \mathrm{~cm}$.

In view of this, the equivalent depth of penetration may be seen as the predominant characteristic of the exchange process in reclamation procedures.

\section{a 2. The modulation of the front for the linear isotherm}

Now the effect $a$ vanishes and the full effect of $b$ and $c$ is felt. These will tend to elongate the exchange front, increasingly with time and, therefore, knowledge of the extent, and also shape, of the front will be of more practical importance than for $a 1$.

The phenomena responsible for the modulation of the front and enumerated under $b$ and $c$ are longitudinal diffusion, dispersion and delayed equilibrium due to rate effects. It will now be necessary to evaluate their relative importance in soils and the way they are influenced by other soil factors.

Among those, the flow velocity of the solution is quite decisive. The whole range of 
flow velocities of soil water is between $10^{-5}$ and $10^{-3} \mathrm{~cm} \mathrm{sec}^{-1}$ (i.e. $1-100 \mathrm{~cm} \mathrm{day}^{-1}$ ) with the low velocities corresponding to moisture redistribution and movement to the root surface, the higher velocities to prolonged infiltration following flooding of the soil.

In comparison, diffusion coefficients of ions such as in the $\mathrm{Na}$ and $\mathrm{Ca}$ bulk solution are around $1 \times 10^{-5} \mathrm{~cm}^{2} \mathrm{sec}^{-1}$, giving with a tortuosity of between $1.3-2.5$ and a capacity factor between $2-10$ an effective longitudinal diffusion coefficient in soil in the order of $4 \times 10^{-6}-4 \times 10^{-7} \mathrm{~cm}^{2} \mathrm{sec}^{-1}$. As most of the convective transport of ions will take place at the higher flow velocities, the value of $D^{*} / \mathrm{v}^{*}$ (HETP) due to longitudinal diffusion will be only of the order of tenths of millimeters. Diffusion will, therefore, only play a role at very low convection rates, i.e. during the redistribution of soil water (Frissel et al., 1970).

The case is different for dispersion, as the magnitude of the dispersion coefficient, $D_{\text {disp }}$, itself is dependent on the flow velocity. Here the value of $D^{*} / \mathrm{v}^{*}$ may reach an order of magnitude from a few millimeters to a few centimeters (Passioura and Rose, 1971; Frissel et al., 1970) and, therefore, this effect will be predominant at the most common flow rates.

As to the rate effect, entering as $D^{*}{ }_{R}$ in the equation, it appears that for cation exchange in soil the diffusion of ions into regions outside the main pathway of convective flow is of only concern. For flow rates up to $10^{-3} \mathrm{~cm} \mathrm{sec}-1$ these regions will usually be in the order of $1 \mathrm{~mm}$. Using $10^{-6} \mathrm{~cm}^{2} \mathrm{sec}^{-1}$ for the value of the intraparticle diffusion coefficient, one would then find $\mathrm{R}$ to be of the order of $0.1 \mathrm{sec}^{-1}$. The corresponding value of $\mathrm{D}^{*} \mathrm{R} / \mathrm{v}^{*}$ is then only $10^{-3} \mathrm{~cm}$ and thus of no practical concern. Only if the main convective transport is located in pores of much larger size, as evidenced by far greater flow rates than suggested above, one might have to take into account 'diffusion regions' considerably greater than $1 \mathrm{~mm}$.

Accordingly, the situation for the linear adsorption isotherm should be covered adequately by Eq. 11 in which the value of $D^{*} / \mathrm{v}^{*}$ (i.e. HETP) is dominated by the dispersion effect during the infiltration, and possibly influenced also by the longitudinal diffusion during redistribution. The shape of the exchange front is now described by a complementary error function combined with a correction term for reflection which is of importance close to the soil surface only, viz within a distance of 25 times the HETP (i.e. 2-20 cm). Beyond this region the spread of the front is easily estimated.

Using the extent of the front covering $90 \%$ of the concentration change occuring as a measure of its spread, $\Delta \mathrm{x}_{\mathrm{s}}$, one finds:

$$
\frac{\Delta \mathrm{x}_{\mathrm{s}}}{\mathrm{x}_{\mathrm{p}}}=4 \sqrt{\frac{\mathrm{D}^{*} / \mathrm{v}^{*}}{\mathrm{x}_{\mathrm{p}}}}
$$

Thus, while the front spread increases with increasing values of $x_{p}$, its relative magnitude decreases. Taking e.g. $D^{*} / \mathrm{v}^{*}$ equal to $0.3 \mathrm{~cm}$, one finds a front spread of $7 \mathrm{~cm}$ at $10-\mathrm{cm}$ depth and one of $10 \mathrm{~cm}$ at $20-\mathrm{cm}$ depth, i.e. the front is located between 15 and $25 \mathrm{~cm}$ depth in the latter case.

\section{a 3. Modulation of the front for the unfavourable isotherm}

While for $a 1$ the exchange front was the result of spreading effects (i.e. diffusion and rate effects) against the sharpening action of a favourable isotherm and in $a 2$ the front was shaped by those spreading effects only, now, in $a 3$ all effects together tend to spread the exchange front. In this flattening process the role of the unfavourable exchange isotherm is often predominant. 
To compare the contribution of the two processes to the flattening of the front, the spreading effect of an unfavourable isotherm alone has to be calculated first. This spread, $\Delta \mathrm{x}_{\mathrm{s}}$, in centimeters, of a front ranging from, for instance $\mathrm{n}_{\mathrm{i}}$ (initial, or minimum, fraction adsorbed in the front considered) to $n_{i}$ (final, or maximum, fraction adsorbed) is given by:

$$
\Delta \mathbf{x}_{\mathrm{s}}=\frac{\mathrm{V} / \varepsilon\left(\mathrm{Q} / \varepsilon \mathrm{C}_{\mathrm{o}}\right)\left(\mathrm{n}_{\mathrm{f}}{ }_{\mathrm{f}}-\mathrm{n}^{\prime}{ }_{\mathrm{i}}\right)}{\left(1+\mathrm{n}^{\prime}{ }_{\mathrm{f}} \mathrm{Q} / \varepsilon \mathrm{C}_{\mathrm{o}}\right)\left(\mathrm{l}+\mathrm{n}^{\prime}{ }_{\mathrm{i}} \mathrm{Q} / \varepsilon \mathrm{C}_{\mathrm{o}}\right)}
$$

in which $\mathrm{n}_{\mathrm{i}}^{\prime} \equiv(\mathrm{dn} / \mathrm{dN})_{\mathrm{i}}$ and $\mathrm{n}_{\mathrm{f}} \equiv(\mathrm{dn} / \mathrm{dN})_{\mathrm{f}}$.

As $n^{\prime}{ }_{i}<<n^{\prime}$ and $\left(Q / \varepsilon C_{o}\right) n_{f}>>1$, this expression may, for practical purposes, be further simplified to:

$$
\Delta \mathrm{x}_{\mathrm{s}} \sim \frac{\mathrm{V} / \varepsilon}{\mathrm{l}+\mathrm{n}_{\mathrm{i}}^{\prime} \mathrm{Q} / \varepsilon \mathrm{C}_{\mathrm{o}}}
$$

The equivalent depth of penetration is given as:

$$
\mathrm{x}_{\mathrm{p}}=\frac{\mathrm{V} / \varepsilon}{\mathrm{I}+\overline{\mathrm{n}^{\prime} \mathrm{Q} / \varepsilon \mathrm{C}_{\mathrm{o}}}}
$$

with $\overline{\mathrm{n}}^{\prime}=\frac{\mathrm{n}_{\mathrm{f}}-\mathrm{n}_{\mathrm{i}}}{\mathrm{N}_{\mathrm{f}}-\mathrm{N}_{\mathrm{i}}}=\Delta \mathrm{q} / \varepsilon \Delta \mathrm{c}$ as defined before. Combining Eq. 16a with Eq. 17 one then finds:

$$
\frac{\Delta \mathrm{x}_{\mathrm{s}}}{\mathrm{x}_{\mathrm{p}}} \sim \frac{1+\overline{\mathrm{n}}^{\prime} \mathrm{Q} / \varepsilon \mathrm{C}_{\mathrm{o}}}{1+\mathrm{n}_{\mathrm{i}}^{\prime} \mathrm{Q} / \varepsilon \mathrm{C}_{\mathrm{o}}}
$$

The spread of the front is therefore proportional to and increasing with depth of penetration.

Using a Gapon exchange-isotherm for $\mathrm{Na}-\mathrm{Ca}$ exchange with $\mathrm{K}_{\mathrm{G}}=1 / 2$ and a distribution ratio of 20 , the relative width of the front $\Delta \mathrm{x}_{\mathrm{s}} / \mathrm{x}_{\mathrm{p}}$ may be calculated as about 3.25 , while the relative spread resulting from other modulating effects and calculated by Eq. 15 would be about 0.45 for a depth of $25 \mathrm{~cm}$ and decreasing with depth. This last value of the spread is furthermore overestimated by neglecting the reflection correction term and by the use of a linear instead of an 'unfavourable' isotherm in this estimate. Therefore, it may be stated that the unfavourable isotherm produces really the predominant effect.

One may arrive at the same conclusion by treating the problem as a non-equilibrium one (cf. case G). As this solution is limited to a second order reversible rate equation (i.e. a Kerr equilibrium exchange isotherm) one first calculates the equivalent second order rate constant for the range of exchange studied. Using a value of a second order rate constant corresponding to a Gapon type exchange with $\mathrm{K}_{\mathrm{G}}=1 / 2$ one may convince oneself that the magnitude of the column capacity and solution capacity parameters $s$ and $t$ and the equilibrium parameter $r$ are such that one may revert to the equilibrium solution which is nothing but a simplified version of case B. As an example, the distribution curve calculated according to the method mentioned under $\mathrm{G}$ by Bower et al. (1957) for Na-Ca exchange could have been obtained straight away from the solution for case $\mathrm{B}$ as is shown in Fig. 2. 


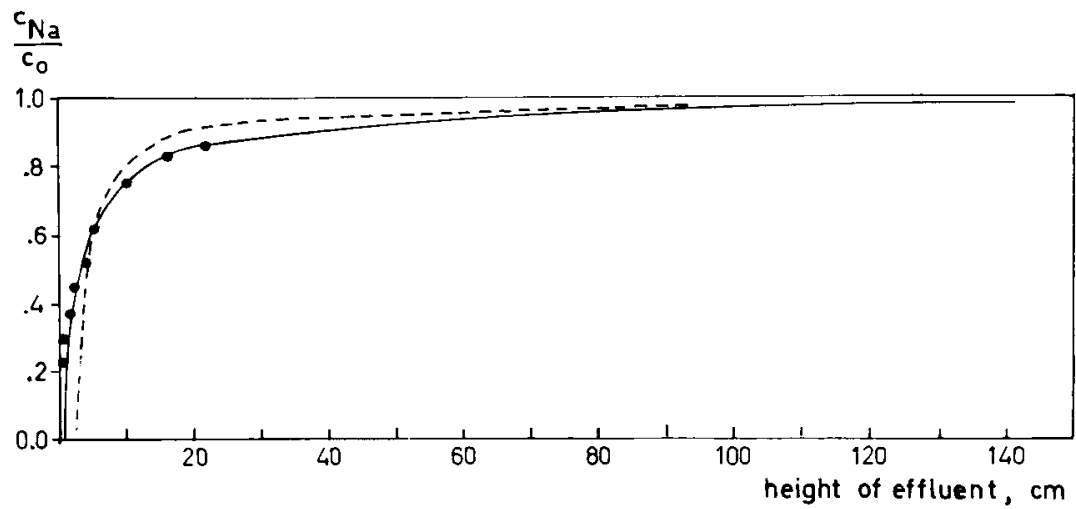

Fig. 2. Comparison of the measured effluent composition with theoretical calculations for $\mathrm{Na}-\mathrm{Ca}$ exchange in Chilcott silt loam.

- experimental points (Bower et al., 1957) — calculated (Bower et al., 1957), $\mathbf{r}_{\text {Kerr }}$ fitted to outflow curve - - calculated, $\mathrm{K}_{\mathrm{G}}=0.45(\mathrm{~mol} / \mathrm{l})^{-1 / 2}$

Summarizing the situation as it prevails usually in soils, one may conclude that:

1. The chromatography process accompanying the exchange of monovalent ions by divalent ones (or more generally, the exchange of ions by others which are much more preferred) is dominated by the formation of a stationary front according to Eq. 12 of case $\mathbf{D}$.

2. The chromatography process accompanying the accumulation of trace components in soil is usually described satisfactorilly by means of the Glueckauf approximation of case $\mathrm{E}$ and $\mathrm{F}$.

3. The chromatography process accompanying the displacement of preferentially held ions (divalent ions) by others which are not preferred ( $\mathrm{Na}$ ions and sometimes $\mathrm{K}$ ions) is dominated to a large extent by the influence of the (unfavourable) exchange isotherm and may thus be described satisfactorily by the equation of case $B$.

For all three cases the estimate of the equivalent depth of penetration, $x_{p}$, is a matter of prime concern, although for the last one the width of the front may become considerably larger than $x_{p}$.

Because of the dominant position of $x_{p}$ an estimate of the electrolyte concentration in the soil profile during exchange and transport may prove to be the limiting factor for predictions based on the use of an appropriate exchange equation.

\section{References}

Aorivos, A., 1960. On the combined effect of longitudinal diffusion and external mass transfer resistance in fixed bed operations. Chem. Engng. Sci. 13: 1-6.

Baver, L. D., 1956. Soil Physics. John Wiley, New York, p. 166

Bischoff, K. B. \& O. Levenspiel, 1962a. Fluid dispersion-generalization and comparison of mathematical models. I. Generalization of models. Chem. Engng. Sci. 17: 245-255.

Bischoff, K. B. \& O. Levenspiel, 1962b. Fluid dispersion-generalization and comparison of mathematical models. II. Comparison of models. Chem. Engng. Sci. 17: 257-264.

Bolt, G. H., 1967. Cation-exchange equations in soil science. A review. Neth. J. agric. Sci., 15: 81-103.

Bower, C. A., W. R. Gardner \& J. O. Goertzen, 1957. Dynamics of cation exchange in soil columns Proc. Soil Sci. Soc. Am., 21: 20-24. 


\section{CHROMATOGRAPHY IN CATION EXCHANGE OF SOILS}

Brenner, H., 1962. The diffusion model of longitudinal mixing in beds of finite length. Numerica! values. Chem. Engng. Sci. 17: 229-243.

Carslaw, H. S. \& J. G. Jaeger, 1959. Conduction of heat in solids, 2nd ed. Oxford University Press, London.

De Vault, D., 1943. The theory of chromatography. J. Am. chem. Soc. 65: 534-540.

Frissel, M. J. \& P. Poelstra, 1967a. Chromatographic transport through soils. I. Theoretical evaluations. Pl. Soil 26: 285-302.

Frissel, M. J. \& P. Poelstra, 1967b. Chromatographic transport through soils. II. Column experiments with $\mathrm{Sr}$ - and Ca- isotopes. Pl. Soil 27: 20-32.

Frissel, M. J., P. Poelstra \& P. Reiniger, 1970. Chromatographic transport through soils. III. A simulation model for the evaluation of the apparent diffusion coefficient in undisturbed soils with tritiated water. $P$. Soil 33: 161-176.

Giddings, J. C., 1967. Physico-chemical basis of chromatography. J. chem. Educarion 44: 704-709.

Glueckauf, E., K. H. Barker \& G. P. Kitt, 1949. Theory of chromatography. VIII. The separation of lithium isotopes by ion exchange and of neon isotopes by low-temperature adsorption columns. Disc. Faraday Soc. 7: 199-213.

Glueckauf, E., 1955a. Principles of operation of ion exchange columns, in: Ion exchange and its applications, p. 34-46. Society of Chemical Industries, London.

Glueckauf, E., 1955b. Theory of chromatography. Part 9. The 'theoretical plate' concept in column separations. Trans. Faraday Soc. 51: 34-44.

Helferich, F., 1962a. Ion exchange. McGraw-Hill, New York.

Helferich, F., 1962b. Theories of ion-exchange column performance: A critical study. Angew. Chem., int. Ed. 1: $440-453$

Helferich, F., 1965. Ion exchange chromatography. Adv. Chromatog. 1: 3-60.

Hiester, N. K. \& T. Vermeulen, 1952. Saturation performance of ion exchange and adsorption columns. Chem. Engng Prog. 48: 505-516.

Hougen, D. A. \& W. R. Marshal Jr, 1947. Adsorption from a fluid stream flowing through a stationary granular bed. Chem. Engng. Prog. 43: 197-208.

Houghton, G., 1964. The additivity of rate and diffusion phenomena in continuous chromatography. J. Chromatog. 15: 5-8.

Klinkenberg, A. \& F. Sjenitzer, 1956. Holding-time distribution of the Gaussian type. Chem. Engng Sci. 5: 258-270.

Lambert, S. M., Porter, P. E. \& R. H. Schieferstein, 1965. Movement and sorption of chemicals applied to the soil. Weeds 13: 185-190.

Lapidus, L. \& N. R. Amundson, 1952. The effect of longitudinal diffusion in ion exchange and chromatographic columns. J. Phys. Chem. 56: 984-988.

Lapidus, L. \& J. B. Rosen, 1954. Ion Exchange. Chem. Engng. Prog., Symp. Ser. 50 (14): 97-102.

Levin, J., 1964. Movement of added nitrates through soil columns and undisturbed soil profiles. Trans. 8th int. Congr. Soil Sci. IV: 1011.

Martin, A. J. P., 1947. The principles of chromatography. Endeavour 6 (21): 21-28.

Mickley, H. S., J. K. Sherwood \& C. E. Reed, 1957. Applied mathematics in chemical engineering, 2nd ed. McGraw-Hill, New York.

Molen, W. H. van der, 1957. The exchangeable cation in soils flooded with sea water, Versl. landbouwk. Ond. 63: 17.

Opler, A., 1953. Application of computing machines to ion exchange column calculations. Ind. Engng. Chem. 45: 2621-2629.

Passioura, J. B. \& D. A. Rose, 1971. Hydrodynamic dispersion in aggregated media. 2. Effects of velocity and aggregate size. Soil Sci. 111: 345-351.

Reiniger, P., 1970. Movement and exchange of sodium and calcium in calcareous and gypseous soils. Ph. D. Thesis, The Hebrew University, Jerusalem, Israel.

Rible, J. M. \& L. E. Davies, 1955. Ion exchange in soil columns. Soil Sci. 79: 41-47.

Ritchie, A. S., 1966. Cromatography as a natural process in geology. Adv. Chromatog. 3: 119-134.

Thomas, H. C., 1948. Chromatography: a problem in kinetics. Ann. N.Y. Acad. Sci. 49 (2): $161-183$.

Thomas, H. C., 1949. The kinetics of fixed-bed ion exchange, theory and application. In: F. C. Nachod (Ed.), Ion exchange, p. 29-43. Academic Press, New York.

Vermeulen, T., 1958. Separation by adsorption methods. Adv. chem. Engng. 2: 147-208.

Walter, J. E., 1945. Multiple adsorption from solutions. J. chem. Phys. 13: 229-234.

Wicke, E., 1939. Empirische und theoretische Untersuchungen der Sorptionsgeschwinddigkeit von Gasen an porösen Stoffen. II. Kolloid. Z. 86: 295-313.

Yaalon, D. H., 1964. Downward movement and distribution of anions in soil profiles with limited wetting. In: Experimental Pedology. Proc. 11th Easter Sch. agric. Sci., Univ. Nott.: 157-164. 